\title{
Evaluation of a Short-term Humanistic Programme for Anger Traits Reduction: A Preliminary Study
}

\author{
Garyfallia Kontou and Michael D Callifronas* \\ The Hellenic Institute for Psychotherapy,30 Kalliga St, 15237 Filothei, Athens, Greece
}

\begin{abstract}
Introduction: Anger is a defensive mechanism for highly stressful and threatening situations and is considered as the most "negative" emotion, difficult to control and often combined to aggressive behavior. However, anger is just a secondary emotion and useful for the organism as a whole. The present study investigates, in presence of a humanistic experiential learning programme, anger as a personality trait that can be reduced, and its hidden power can be unleashed in order to proceed to active experimentation. This study is based on the hypothesis that anger is considered as an alarm signal indicating unmet needs.
\end{abstract}

Results: Using the STPI instrument for measurements, a significant reduction of the mean personality trait scores for anger $(p=0.029, N=35)$ after eight sessions of the programme has been observed. The mean scores reduction was higher $(p=0.01, N=32)$ in participants who showed a higher mean score of anger $(\geq 2)$ at the pre intervention measurements.

Conclusion: This is a preliminary study showing that a short-term (eight sessions) humanistic experiential learning programme for anger may have a significant effect on the reduction of anger as a personality trait. Anger reduction is a result of lower subcortical activity, and opens the gate for the elaboration of beliefs into cortical areas of the brain. Cortical areas can offer a higher degree of freedom of choice and responsibility for more functional behaviours.

Keywords: Anger; Personality Traits; Humanistic; Person-centred; Group-centred; Experiential learning

\section{Introduction}

Anger is considered to be the most common "negative" emotion expressed in humans, followed by anxiety and sorrow [1-6]. This feeling is a defensive mechanism for highly stressful and threatening situations, and prevents further loss by modifying behaviour effectively [7] Fear and anger motivate and trigger fight-or-flight tendencies. Parallel and negative internal states (e.g. pain and social stress) increase the probability of anger and its manifestations to aggression $[8,9]$. According to Scherer and Wallbott [6] anger is the most dominant and difficult feeling to control, in which other "negative" emotions are usually integrated. Emotions that may be entailed in anger include disappointment, fear, anxiety, despair, awkwardness, pessimism, insecurity, jealousy, rejection and sadness [10]. Ramirez et al. [11] point out that, this natural emotion is not always beneficial to human health. Poisons are natural as well, but deadly nonetheless. Therapists are often confronted with this highly complex emotion, and the effects it has on clients and their relationships.

However, anger can be useful since it can be considered as an alarm signal for emotions, needs and values that are threatened [12], and promotes the effort to set boundaries within human relationships, if one can control it. Then, it can become a facilitating tool for the acknowledgment of needs and feelings like fear, shyness, frustration, disappointment etc. [13], and provide the strength and the choice to make necessary changes in a person's life, such as jobs, environment, homes and relationships.

The person needs to undertake the exclusive responsibility for the development of his own values and goals, which will be the result of his own free will [14]. As Kirscehnbaum and Henderson [15] explain, Rogers considered personal choice to be the ultimate expression of freedom: "everything might be taken from a man, but one thing: the last of the human freedoms - to choose one's attitude in any given set of circumstances, to choose one's own way" [16]. Humans have the choice, hence the responsibility, to decide if their behaviour will be aggressive or assertive. Therapy and anger management through experiential learning can facilitate this process.

Even though there is a variety of literature distinguishing between the situation of fear and the personality trait of anxiety, as well as the state of sorrow and personality trait of depression [5], there is no equivalent distinction for the word "anger". In fact, the word "anger" is defined both as a situation, and a personality trait [5].

Haines [17] discusses two types of anger: temporary and trait anger. Temporary anger appears based on a certain situation. Trait anger indicates more intense levels of anger within the person. Spielberger and Reheiser [18] postulate a definition: "State anger (S-Anger) is defined as a psychobiological state or condition, consisting of angry feelings that may vary in intensity, from mild irritation or annoyance to fury and rage, with associated activation of the autonomic nervous system. Trait anger (T-Anger) is defined in terms of individual personality differences in the frequency that State Anger was experienced over time". Intense physical aggression is a common behavior reported in this case, along with negative verbal responses, drug use and negative consequences of anger expression.

*Corresponding author: Dr. Michael Callifronas, 30 Kalliga St, 15237 Filothei, Athens, Greece, Tel: +306944674180; E-mail: michael@Callifronas.com, Liana Kontou, 24, L. Bellou St., 11524, Athens, Greece, E-mail: garyf.kontou@gmail.com Received August 01, 2017; Accepted August 14, 2017; Published August 20 , 2017

Citation: Kontou G, Callifronas MD (2017) Evaluation of a Short-term Humanistic Programme for Anger Traits Reduction: A Preliminary Study. J Ment Disord Treat 3: 141. doi:10.4172/2471-271X.1000141

Copyright: $\odot 2017$ Kontou G, et al. This is an open-access article distributed under the terms of the Creative Commons Attribution License, which permits unrestricted use, distribution, and reproduction in any medium, provided the original author and source are credited. 
To summarize, anger tends to affect relationships, health and job in a negative way [19]. This paper examines a group-centred procedure that addresses direct changes in anger traits.

From the researchers' point of view, anger is connected with basic human needs, as described in Maslow's Theory of Human Motivation [2]. Therefore, anger is considered to be an alarm signal indicating unmet needs, as classified by Maslow, in a pyramid of five sets [2].

More specifically, a psychological threat can be produced simply through the possibility of thwarting these needs, or through an emanate danger to the defenses that protect them. This threat triggers the general emergency reactions [2] i.e. anxiety and anger. People resent the idea when someone else controls the means for the gratification of their needs, because they wish to retain control themselves. They seek independence and feel threatened when they depend on others [20].

Anger expresses discontent and is directed towards those who exert power on others. It appears to be a learned and universal response of people of all ages against someone who attempts to obstruct the satisfaction of their needs [14].

Rogers [21] believed that the basic factor for our malicious behaviour is cultural influence: "I have gradually come to see this dissociation, rift, estrangement (between self-structure and experience) as something learned, a perverse channelling of some of the actualizing tendency into behaviours which do not actualize... Now I believe that individuals are culturally conditioned, rewarded, reinforced, for behaviours which are in fact perversions of the natural directions of the unitary actualizing tendency". Our acquired beliefs show us the path to satisfy our basic needs. Epictetus stated that we do not get angry with what is happening around us, but with the viewpoint through which we perceive it [22]. These beliefs are defined according to the personcentred approach as subjective perceptions and therefore, different for each person. They are shaped by her/his own position in the world, her/ his worldview, her/his values, and the introjections of the significant others during her/his lifetime [23]. This process can create distorted beliefs resulting in the development of the "conditions of worth" and values, which the person internalizes as if they were products of his free and independent choice [24]. The person considers these "rigid" values as definitive and defends them -very often with anger- without really examining or questioning them each time she/he undergoes a new experience.

McKay and Maybell [25] describe an internal process in all individuals as follows: Belief leads to emotion which leads to behaviour $[26,27]$. The transition from belief to emotion often happens as a fast and unconscious process. A deeper awareness of distorted beliefs is necessary in order to acknowledge emotions and control behaviour. Moreover, our beliefs show us the alternative ways to satisfy our needs (e.g. A man believes that driving an expensive car would be important in order to connect with the right woman, while another man believes that he can achieve the same target through good knowledge of relationships). Therefore, one could argue that the satisfaction of our organismic needs is accomplished through the pathway of our individual perception, which involves the satisfaction of each need. So, these perceptions trigger emotion, which in turn triggers behaviour. Therefore, the above-mentioned internal process can be converted as follows: Belief about the Need-Satisfaction leads to Emotion (e.g. Anger), which leads to Behaviour (e.g. Active or Passive Agressiveness).

There is a variety of research on anger management groups over the last 30 years, based on the work of Novaco [28], and CBT-related interventions are implemented with some variations by contemporary therapists of different approaches. Among them, a great number of studies investigates anger management groups from the viewpoint of maladjustment or psychopathology. However, it is still unclear which therapeutic model is the most effective in treating anger problems. A meta-analytic review, concerning 96 studies and 139 treatment effects, showed that the overall mean effect on anger management was moderate [29].

Despite their proliferation during the last two decades, group interventions for anger problems have been relatively omitted, compared to those for other emotional disorders [30]. Furthermore, a research gap has been detected between humanistic psychology and anger intervention groups. Thus, the contribution of the present study in the field aims to give prominence to another viewpoint on anger group interventions.

The therapeutic nature of the programme applied in this study, is more experiential and less theoretical. The training of these groups is approached in a non-directive way with acceptance of what is said, restatement of content, and clarification of feelings [23]. Rogers [31] suggested that the most personal and unique elements in each individual, if shared and expressed, could "deeply speak to others". Hence, "what is most personal is most general" [31].

Schmid and O'Hara [32] state that person-centred therapy “..is, in its essence, a social approach, an approach relating to groups, and thus a 'group approach' which also happens to be applicable to relationships between two people (dyads, pairs), as special types of groups". Moreover, Rogers [33] has proved that training groups with intensive group experiences have therapeutic results. Taking into consideration the aforementioned viewpoint, this study aims to show that the personcentred and group-centred principles are applicable in either therapy or experiential learning.

In fact, there is limited research relating to experiential learning groups in the field of humanistic psychotherapy. Callifronas and Kontou [12] in a recent study investigated the changes in personality traits after a two-phase experiential learning programme consisting of 20 meetings. The first phase was dedicated to the acknowledgement of anger traits in each participant, while the second phase proceeded to therapeutic (psychoeducative) intervention using experiential learning methods. This study examined three different groups over a period of three years (2011, 2012, and 2013). Results showed a significant difference between pre and post-Test scores $(\mathrm{t}(29)=3.63, \mathrm{p}<0.001)$. The effect size was large $(\mathrm{d}=0.707)$, which suggests that a decrease in anger traits tended to be repeated in every group.

\section{Materials and Methods}

\section{The group-centred programme}

The experiential learning programme related to this study has been developed by Dr. Michael Callifronas and the Hellenic Institute for Psychotherapy, and is active in collaboration with several municipalities of Attica for the last ten years. It has provided a new perspective on the effects of a PC experiential learning on anger, and offers the opportunity to directly investigate the effects on personality traits.

Overall, the programme is developed in three phases. The $1^{\text {st }}$ phase is Acknowledgment, the $2^{\text {nd }}$ Therapy and the $3^{\text {rd }}$ Assertiveness (a total of 32 sessions). In this paper, the results concerning the $1^{\text {st }}$ phase, comprising of eight two-hour sessions, are being measured.

In this $1^{\text {st }}$ phase, members are facilitated to acknowledge the 
frequency of their anger, its intensity and duration. They are also facilitated to become aware of what makes them angry and how they will recognize their anger during its early stage of biological process, named irritation. They share their experiences with the group and deepen their meaning through reflection. They discover deeper feelings and needs covered by the expression of anger that had not been recognized before. Then, they move into acceptance, thus, acknowledge the subjectivity of anger and the possible options for its release. As they comprehend and experience anger in their everyday lives, they change feelings, values and behaviour, thus move from theory to action. This way they approach the stage of active experimentation [1]

The programme directly implements the person-centred principles which are considered necessary and sufficient to promote growth. Concretely, a combination of knowledging concerning anger, along with group therapy principles provided by person-centred therapists, create the appropriate atmosphere for participants to make personality changes.

\section{Participants}

A total of 35 women participated in this study. They all registered to follow the $1^{\text {st }}$ phase of a group-centred programme for anger, and were allocated in two separate groups of 17 and 18 members for the years 2014 and 2015 respectively. No selection was performed, and they had never estimated their levels of anger on standardized anger measurements prior to registration in this specific programme. Their age varied from 32 to 56 years old and they were all of middle socialeconomic status. An independent samples t-test showed that the mean ages of the two groups $(\mathrm{A}=17$ and $\mathrm{B}=18)$ are not significant different thus, both groups have almost equal mean ages and can be examined as a whole group with a mean age \pm SD: $40.80 \pm 5.63$ (Tables 1-3).

All participants had at least secondary education and lived in the northern suburbs of Athens. In addition, most participants had group experience through groups on parental skills, communication skills, boundaries and self-esteem development.

\section{Procedure}

Participants were separated into two groups. Two person-centred psychotherapists acted as facilitators in both groups.

Group members were handed a self-analysis State-Trait Personality Inventory (STPI) questionnaire at the beginning of the first phase (awareness and acknowledgement) and at the end of it (end of eight sessions). In order to ensure the blind procedure and anonymity, key numbers were given to answered STPI questionnaires. Since all sheets

\begin{tabular}{|l|c|c|c|c|c|}
\hline \multicolumn{7}{|c|}{ Group Statistics } \\
\hline \multirow{2}{*}{ AGE } & GROUP & N & Mean & Std. Deviation & Std. Error Mean \\
\cline { 2 - 7 } & A & 17 & 39.94 & 4.548 & 1.103 \\
\cline { 2 - 6 } & B & 18 & 41.61 & 6.527 & 1.538 \\
\hline
\end{tabular}

Table 1: Mean Ages of Groups A (2014) \& B (2015). were coded, anonymity was protected even after the intervention is finished (e.g. publicity). Moreover, it was made clear that participants had the right to withdraw their participation to the study at any point.

\section{Measures}

In order to measure anger as a personality trait, a self-administered State-Trait Personality Inventory (STPI) was used [3]. The copies of STPI questionnaires were provided with permission of the publisher. This tool consists of 80 questions designed to measure transitory and dispositional anger, anxiety, curiosity and depression in a four-point frequency scale ranging from 1-4 [18]. For this study, the alteration of anger as personality trait was examined. The personality trait is represented in STPI by the T-Anger variable, which measures dispositional anger. The T-Anger variable consists of 10 items which measure individual differences in anger as a personality trait. It allows the examination of individual differences in the way people tend to experience anger without specific provocation, e.g. "I am a hot-headed person" or "I have a fiery temper" [3]. The score ranges from 10 to 40 points.

The culmination of Anger questions entailed in STPI, is also included in the STAXI quest [34], which has been used for Greek populations. Research by Bezevegis et al. [35] has provided evidence for the validity of the STAXI scale in the Greek language (36). Furthermore, Vassilopoulos et al. [36] used STAXI to evaluate a short anger management group for special education teachers in Greece. Moreover, a study by Callifronas and Kontou [12] administrated STPI inventory in three consecutive years (2011 through 2013) to examine anger in Greek group-centred settings.

The statistical analysis of the data was performed using the Statistical Package for Social Sciences (SPSS) program, where $p \leq 0.05$ was considered statistically significant. The SPSS Paired sample t-test was implemented to both samples of subjects to measure changes in mean scores of T-Anger during eight sessions of the programme.

\section{Results}

The present study examines the results of a sample of 35 subjects and a subsample of 31 subjects. Mean values of anger personality traits of the first sample $(\mathrm{N}=35)$ pre and post intervention revealed a starting mean level of $2.643 \pm 0.544$ and an ending mean level of $2.460 \pm 0.583$. The mean difference between the pre-Test and post-Test scores was $0.183 \pm 0.475(\mathrm{t}(34)=2.278, \mathrm{p}=0.029)($ Tables 4 and 5$)$.

The results of a subsample $(\mathrm{N}=31)$ of the participants showing a starting anger trait level of $\geq 2$ in STPI were also measured. Mean values of anger personality traits of this subsample pre and post intervention demonstrated a starting mean level of $2.745 \pm 0.490$ and an ending mean level of $2.532 \pm 0.532$. Accordingly, they showed a pre-Test and post-Test mean difference of $0.213 \pm 0.423(\mathrm{t}(30)=2.276$, $\mathrm{p}=0.01)($ Tables 6 and 7).

\begin{tabular}{|c|c|c|c|c|c|c|c|c|c|c|}
\hline & & \multicolumn{9}{|c|}{ Independent sample Test } \\
\hline & & \multicolumn{2}{|c|}{$\begin{array}{c}\text { Levenes's Test for equality of } \\
\text { variance }\end{array}$} & \multicolumn{7}{|c|}{ t-test for equality of means } \\
\hline & & $\mathbf{F}$ & sig & $\mathbf{t}$ & df & $\begin{array}{c}\text { Sig } \\
\text { (tailed) }\end{array}$ & $\begin{array}{c}\text { Mean } \\
\text { difference }\end{array}$ & $\begin{array}{l}\text { Std. Error } \\
\text { difference }\end{array}$ & $95 \%$ conf & $\begin{array}{l}\text { interval of } \\
\text { cee }\end{array}$ \\
\hline \multirow[t]{3}{*}{ AGE } & & & & & & & & & Lower & Upper \\
\hline & $\begin{array}{l}\text { Equal variance } \\
\text { assumed }\end{array}$ & 3.194 & 0.83 & -0.873 & 33 & 0.389 & -1.67 & 1.912 & -5.561 & 2.221 \\
\hline & \multicolumn{2}{|c|}{ equal variance not assumed } & & 0.882 & 30.43 & 0.385 & -1.67 & 1.893 & -5.534 & 2.194 \\
\hline
\end{tabular}

Table 2: Significance of Age Variables of Groups A (2014) and B (2015) 
The Reliability test of the sample was investigated through SPSS. Cronbach's alpha was 0.822 (Table 8 ), which indicates an acceptable level $(>0.7)$ of internal consistency coefficient for this scale with this specific sample [37].

\section{Discussion}

The results of this study support the hypothesis that this eight session (short-term) group-centred experiential learning programme for anger might have a significant effect on the reduction of anger as a personality trait. The overall sample $[\mathrm{N}=35]$.

The overall sample [ $\mathrm{N}=35]$ investigated in the present study, revealed an $6.92 \%$ mean reduction $(\mathrm{p}=0.029)$. Moreover a $7.76 \%$ mean reduction $(\mathrm{p}=0.01)$ in anger personality traits pre and post intervention was observed in the subgroup of participants showing a starting anger traits score of $\geq 2(\mathrm{~N}=31)$. In this subgroup four [4] participants whose mean anger score prior to intervention was less than 2 , were excluded. This is a purposive sampling technique which is also called "judgment sampling", as it allows for the "deliberate choice of an informant due to the qualities the informant possesses" [38]. This purposive sampling is a nonrandom technique which does not require underlying theories or a set number of informants and permits the construction of a sample with a particular characteristic [38]. For the needs of this study and for

\begin{tabular}{|c|c|c|}
\hline \multicolumn{3}{|c|}{ Report } \\
\hline \multicolumn{3}{|c|}{ Age } \\
\hline Mean & N & Std. Deviation \\
\hline 40.80 & 35 & 5.635 \\
\hline
\end{tabular}

Table 3: Mean age of the sample.

\begin{tabular}{|c|c|c|c|c|c|}
\hline \multicolumn{7}{|c|}{ Paired Samples Statistics } \\
\hline \multirow{2}{*}{ Pair 1 } & Mean & N & Std. Deviation & Std. Error Mean \\
\cline { 2 - 6 } & averageA & 2.643 & 35 & .5441 & .0920 \\
\cline { 2 - 6 } & averageB & 2.460 & 35 & .5837 & .0987 \\
\hline
\end{tabular}

Table 4: Mean Scores of Pre $(A)$ and Post $(B)$ Intervention $(N=35)$. comparison reasons, a sample $(\mathrm{N}=31)$ of participants with high levels of anger was needed, since papers found in literature, have utilized samples of populations with higher levels of anger presenting aggressive and/or antisocial behaviour [39]. In addition, a meta-analysis study by Hofmann et al. [40] revealed that the vast majority of research on the subject assessed participants on standardized anger measurements prior to intervention and chose members with higher anger levels [40].

Callifronas and Kontou, [12] illustrated a highly significant $(\mathrm{p}<.001)$ overall change of $13.6 \%$ in anger personality traits with an important effect size (0.707). In their study, a group-centred, two phase (20 sessions) programme was implemented. The present study indicates that significant change has already started from the first phase (eight sessions) of this same programme.

The findings in two meta-analytic reviews [41] showed moderate effectiveness in comparison to other treatments and suggested that CBT may be most effective for patients with issues regarding anger expression [40]. A cognitive-behavior short-term (six sessions) therapeutic approach was able to find significant results in anger control, but not in trait anger compared to anger control [42]. Similarly, other short-term CBT-related therapies provided results for state anger but not for trait anger [43,44]. Vassilopoulos et al. [36] developed a CBT-related psychoeducation anger management group that showed "a significant decrease in the amount of anger experienced (T-Anger) over the course of intervention, compared to a test-retest control group" in four sessions. However, it is a very short-duration, two-week programme and the personality change, as well as its stability, needs to be explained. The present study revealed that the person-centred experiential learning programme had significant results in reducing mean level of anger traits in eight sessions.

In a meta-analytic review demonstrated by Saini [29], results supported eight sessions as an adequate amount of treatment to demonstrate positive results to reduce anger problems. The mean number of treatment sessions was 8.5. This is supported by the evidence that, as treatments increase in the number of sessions

\begin{tabular}{|c|c|c|c|c|c|c|c|c|}
\hline & & & \multirow{2}{*}{$\begin{array}{l}\text { Paired sample test } \\
\text { Paired Difference }\end{array}$} & \multicolumn{2}{|c|}{$95 \%$ confidence interval of the Difference } & \multirow[b]{2}{*}{$\mathrm{t}$} & \multirow[b]{2}{*}{ df } & \multirow[b]{2}{*}{ Sig. (2-tailed) } \\
\hline & & & & Lower & Upper & & & \\
\hline & Mean & Std. Deviation & Std Error Mean & & & & & \\
\hline $\begin{array}{c}\text { Pair } 1 \text { averageA- } \\
\text { AverageB }\end{array}$ & 0.18 & 0.475 & 0.0803 & 0.0197 & 0.346 & 2.278 & 34 & 0.029 \\
\hline
\end{tabular}

Table 5: Significance of the paired T-test $(\mathrm{N}=35)$.

\begin{tabular}{|c|c|c|c|c|c|}
\hline \multicolumn{9}{|c|}{ Paired Samples Statistics } \\
\hline \multirow{2}{*}{ Pair 1 } & & Mean & N & Std. Deviation \\
& averageAover2 & 2.745 & 31 & .4905 & .0891 \\
\cline { 2 - 5 } & averageBover2 & 2.532 & 31 & .5319 & .0955 \\
\hline
\end{tabular}

Table 6: Mean Scores of Pre $(A \geq 2)$ and Post $(B \geq 2)$ Intervention $(N=31)$.

\begin{tabular}{|c|c|c|c|c|c|c|c|c|}
\hline & & & \multirow{2}{*}{$\begin{array}{c}\text { paired sample } \\
\text { test }\end{array}$} & \multicolumn{2}{|c|}{$95 \%$ confidence interval of the Difference } & \multirow[b]{2}{*}{$\mathrm{t}$} & \multirow[b]{2}{*}{ df } & \multirow[b]{2}{*}{ sig.(2-tailed) } \\
\hline & & & & lower & upper & & & \\
\hline & Mean & std.Deviation & std Error Mean & & & & & \\
\hline $\begin{array}{c}\text { pair } 1 \text { averageAover2 } \\
\text {-AverageBover2 }\end{array}$ & 0.21 & 0.4295 & 0.0771 & 0.0554 & 0.371 & 2.76 & 30 & 0.01 \\
\hline
\end{tabular}

Table 7: Significance of the Paired T-test $(\mathrm{N}=31)$.

Reliability Statistics

\begin{tabular}{|c|c|c|}
\hline \multicolumn{3}{|c|}{ Reliability Statistics } \\
\hline Cronbach's Alpha & Cronbach's Alpha Based on Standardized Items & N of Items \\
\hline .822 & .824 & 10 \\
\hline
\end{tabular}

Table 8: Cronbach's alpha Reliability Statistics. 
beyond the average mean of eight, so does the attrition rate creating a higher number of withdrawals from the study. As Saini [29] suggests, "professionals are likely to improve outcome scores when they conduct at least eight sessions, use manuals and fidelity checks to ensure consistency".

As Saini [29] states, the treatment of anger should be approached uniquely and not remain in the shadow of treatments for aggression, hostility, and violence. The present study has provided a different viewpoint on the emotion of anger and a new perspective on anger group interventions, considering anger as a secondary emotion that entails other emotions. As this was a group-centred programme, it focused on personality changes and not on the behaviour. The programme was based on the core conditions that facilitate a growth-promoting climate in therapeutic settings [23]. In this short-term phase, participants were able to acknowledge their anger and distinguish it from their unmet needs.

In addition, person-centred treatment provides a holistic point of view that facilitates personality changes. Clients are not treated as aggressive or antisocial according to their behaviour. It can be assumed that research combined with a group-centred programme might, also, broaden the implementation of the approach. A systematic research on treatments measuring anger as a personality trait might indicate a new perspective in investigating anger.

The present study was developed in a period, which was a crucial year for the country's financial future ( Capital Control Measures) and which is included in the socio-economic crisis period as well. It is made apparent that the programme was very helpful in overcoming difficult long-lasting situations (such as socio-economic crisis), which trigger anger, by making personality changes.

Person-centred theory has argued that the source of the discomfort that often brings individuals to therapeutic settings, are products of the experiences they have had with the environment and their significant others [23]. Hence, members (all females) shared with the group their feelings and thus, shaped a new perception about their self.

Person-centred therapists trust the actualizing tendency of the members in the group. They believe in their own motivational force towards development and change, their effort to approach the "fully-functioning person" [31]. Through the sharing of feelings and experiences, their reflective deepening and conceptualized learning, group-centred elaboration and respecting the content of narration of each member, the group members discovered the close connection between the deeply personal and the universal-collective [31]. They expressed primary emotions that hide behind anger (e.g. disappointment, fear, anxiety, despair, awkwardness, pessimism, insecurity, jealousy, rejection, sadness) that had never been expressed up to that moment [23]. They finally accept their feelings related to needs and values and consequently, take control and strengthen their personal power by making decisions based on their internal locus of evaluation and volition.

As each member experienced the group atmosphere, she was able to acknowledge the need for interdependence, embrace her feelings and develop a need for "collective power" [45] with the people closest to her. Overall, it appears that participants were able to advance in their personal development.

According to Rogers' personality theory [23]: "behaviour is basically the goal-directed attempt of the organism to satisfy its needs as experienced in the field, as perceived". In the present paper, a preliminary report of the therapeutic outcome is presented after the end of the first eight sessions, which represents the first phase of this programme, the acknowledgement of anger traits. As previously said, it is developed around the hypothesis that anger is an alarm signal indicating unmet needs. Group members learn to link anger situations with human needs.

\section{Limitations and Proposals}

The number of subjects seems to be small in order to show that the outcome is repeatable. A larger sample of groups and participants is needed to establish the reliability of this programme in eight sessions. A larger population could provide statistically higher significant results. Another limitation is the lack of a control group which may affect the validity of the intervention. Furthermore, it would be interesting to compare results of groups participating in two different therapeutic approaches. Specifically, T-anger could be examined between PC and CBT groups that have similar samples and same number of sessions, and compare the results.

\section{Conclusion}

Results of this preliminary study show the effectiveness of person-cented groups and allow a humanistic perspective on anger treatment. Even though several limitations were discussed, this study provides important elements on the contribution of a group-centred programme in the reduction of anger, and on personality changes. Moreover, this approach delivers significant results on the reduction of anger as a personality trait in eight sessions. This paper can contribute to the development of humanistic short-term programmes for anger management, and a deeper understanding of the process of anger personality change in a group-centred setting.

It can also be used as a starting point for further research that can lead to the development of an evidence-based, manualised, short term group centred programme for anger.

This paper contains parts of a Master of Science Degree dissertation in Person-Centred Counselling (Univesity of Strathclyde, Glasgow, UK).

\section{References}

1. Kolb DA (1984) Experiential learning: Experience as the source of learning and development. Pearson, New Jersey.

2. Maslow AH (1943) A Theory of Human Motivation. Psychological Review 50 370-396.

3. Spielberger CD (1995) State-Trait Personality Inventory: Inventory and Scoring (Measurement Instrument). Mind Garden Inc., Menlo Park, USA.

4. Deffenbacher J, Stark R (1992) Relaxation and cognitive-relaxation treatments of general anger. Journal of Counseling Psychology 39: 158-167.

5. DiGiuseppe R, Tafrate R (2007) Understanding Anger and Anger Disorders Oxford University Press, NY.

6. Scherer KR, Wallbott HG (1994) Evidence for universality and cultural variation of differential emotion response pattering. Journal of Personality and Social Psychology 66: 310-328.

7. Nesse RM, Williams GC (1996) Why we get sick: The new science of Darwinian medicine. Vintage Books, New York.

8. Berkowitz $L$ (1990) On the formation and regulation of anger and aggression: A cognitive-neoassociationistic analysis. American Psychologist 45: 494-503.

9. Berkowitz L, Harmon-Jones E (2004) Toward an understanding of the determinants of anger. Emotion 4: 107-130.

10. Wilhelm P, Schoebi D, Perrez M (2004) Frequency estimates of emotions in everyday life from a diary method's perspective: A Comment on Scherer et al.'s (2004) survey study: "Emotions in everyday life". Social Science Information 43: $647-665$ 
Citation: Kontou G, Callifronas MD (2017) Evaluation of a Short-term Humanistic Programme for Anger Traits Reduction: A Preliminary Study. J Ment Disord Treat 3: 141. doi:10.4172/2471-271X.1000141

Page 6 of 6

11. Ramirez JM, Santisteban C, Fujihara T, Van Goozen S (2002) Differences between experience of anger and readiness to angry action: A study of Japanese and Spanish students. Aggressive Behavior 28: 429-438.

12. Callifronas MD, Kontou G (2016) Psychoeducative Programme in Anger Management. Journal of Psychology \& Psychotherapy 6: 237-242.

13. Novaco RW (1994) Anger as a risk factor for violence among the mentally disordered. In: Monahan J, Steadman HJ (eds.) Violence and mental disorder: developments in risk assessment. University of Chicago Press, Chicago, IL.

14. Merry T (2006) Invitation to Person-Centred Psychology. PCCS Books, UK.

15. Kirsvhenbaum H, Handerson V (1989) The Carl Rogers Dialogues. Houghton Mifflin, Boston

16. Merry T (2002) Invitation to Person-Centred Psychology Kastaniotis, Athens

17. Haines M (2000) Gender and gender role in relation to anger and anger expression (Unpublished doctoral thesis). Colorado State University.

18. Spielberger CD, Reheiser EC (2009) Assessment of Emotions: Anxiety, Anger, Depression and Curiosity. Applied Psychology: Health and Well-Being 1: 271-302.

19. Holloway JD (2003) Advances in anger management. Researchers and practitioners are examining what works best for managing problem anger. Monitor 34: 54

20. Gordon T (2009) Parent Effectiveness Training. Erevnites, Athens.

21. Rogers CR (1963) The concept of the fully functioning person. Psychotherapy: Theory. Research and Practice 1: 17-26.

22. Kassinove H, Sukhodolsky DG (1995) Anger disorders: basic science and practice issues. In: Kassinove $\mathrm{H}$ (ed.) Anger disorders: definitions, diagnosis, and treatment. Taylor \& Francis, Washington, DC.

23. Rogers CR (1951) Client-Centered Therapy. Constable, London, UK.

24. Rogers CR (1959) A Theory of Therapy, Personality, and Interpersonal Relationships, as Developed in the Client-Centered Framework. Psychology: A Study of a Science 1: 184-256.

25. McKay GD, Maybell SA (2008) Calming the Family Storm. Impact Publishers, Atascadero, California.

26. Ellis A (1958) Rational psychotherapy. The Journal of General Psychology 59: $35-49$.

27. Ellis A (1991) The revised ABC's of rational-emotive therapy (RET). The Journal of Rational-Emotive and Cognitive-Behavior Therapy 9: 139-172.

28. Novaco RW (1985) Anger and its therapeutic regulation. In: Chesney MA Rosenman $\mathrm{RH}$ (eds.) Anger and hostility in cardiovascular and behavioral disorders. Hemisphere Press, Washington, DC.

29. Saini M (2009) A meta-analysis of the psychological treatment of anger: developing guidelines for evidence-based practice. The Journal of the American Academy of Psychiatry and the Law 37: 473-488.

30. Howells K, Day A (2003) Readiness for anger management: Clinical and theoretical issues. Clinical Psychology Review 23: 319-337.

31. Rogers C (1961) On Becoming a Person. Constable, UK

32. Schmid P, O'Hara M (2007) Group Therapy and Encounter Groups. In: Cooper M, O' Hara M, Schmid P, Wyatt G (eds.) The Handbook of Person-Centred Psychotherapy and Counselling. Palgrave Macmillan, UK.

33. Rogers C (1970) On Encounter Groups. Diodos, Athens.

34. Spielberger CD (1988) Manual for the State-Trait Anger Expression Inventory (STAXI). Psychological Assessment Resources, Odessa, FL.

35. Besevegis EG, Dalla M, Gari A, Karademas EC (2008) The adaptation of the State-Trait Anger Expression Inventory (STAXI-2) in the Greek language. Psychology 15: 171-187.

36. Vassilopoulos SP, Brouzos A, Moberly NJ, Tsiligiannis G (2015) Development and evaluation of a short anger management group for special education teachers in Greece: A preliminary study. International Journal of School and Educational Psychology 3: 107-116.

37. Cronbach LJ (1951) Coefficient alpha and the internal structure of tests. Psychometrika 16(3): 297-334.

38. Tongco D (2007) Purposive Sampling as a Tool for Informant Selection Ethnobotany Research \& Applications 5: 147-158.

39. Wilso, C, Gandolfi S, Dudley A, Thomas B, Tapp J, et al. (2013) Evaluation of anger management groups in a high-security hospital. Criminal Behaviour and Mental Health 23: 356-371.

40. Hofmann SG, Asnaani A, Vonk IJJ, Sawyer AT, Fang AA (2012) The Efficacy of Cognitive Behavioral Therapy: A Review of Meta-analyses. Cognitive Therapy Research 36: 427-440.

41. Del Vecchio T, O'Leary KD (2004) Effectiveness of Anger Treatments for Specific Anger Problems: a meta-analytic review. Clinical Psychology Review 24: 15-34.

42. Mitrani ATA (2010) Outcome of anger management training program in sample of undergraduate students. Procedia-Social and Behavioral Sciences 5: 339-344.

43. Shokoohi-Yekta M, Parand A, Zamani N (2010) Anger management instruction for mothers: a cognitive behavioural approach. Procedia Social and Behavioral Science 5: 1371-1375

44. Willner P, Rose J, Jahoda A, Kroese BS, Felce D, et al. (2013). A cluster randomised controlled trial of a manualised cognitive behavioural ange management intervention delivered by supervised lay therapists to people with intellectual disabilities. Health Technology Assessment 17: 1-173.

45. Natiello P (1990) The person-Centred Approach, Collaborative Power and Cultural Transformation. Person Centred Review 5: 268-286. 